Original Article

Artigo Original

Flávia Pereira da Costa ${ }^{1}$ Giovana Diaféria ${ }^{1,2,3}$

Mara Behlau ${ }^{1,2}$

Keywords

Voice

Speech

Dysphonia

Protocols

Parkinson's Disease

Descritores

Voz

Fala

Disfonia

Protocolos

Doença de Parkinson
Correspondence address:

Flávia Pereira da Costa

Centro de Estudos da Voz

Rua Machado Bittencourt, 361, $10^{\circ}$ andar, Vila Mariana, São Paulo (SP), Brazil, CEP: 04044001.

E-mail: flaviapdacosta@yahoo.com.br

\section{Communicative aspects and coping strategies in patients with Parkinson's disease}

\section{Aspectos comunicativos e enfrentamento da disfonia em pacientes com doença de Parkinson}

\begin{abstract}
Purpose: To investigate, in patients with Parkinson's disease (PD), the coping strategies; the most reported vocal symptoms; and the relation between coping, voice symptoms, and communicative aspects. Methods: Seventythree subjects were included in the sample, 33 of which were participants in the experimental group (EG) with diagnosis of PD and 40 were control subjects, that is, healthy and without vocal complaints. They underwent the following procedures: application of Voice Symptoms Scale (VoiSS), Brazilian Version; Voice Disability Coping Questionnaire (VDCQ), Brazilian Version; and the questionnaire Living with Dysarthria (LwD). Results: The EG presented deviations in all protocols: VDCQ, with the most frequently coping strategy being "selfcontrol," VoiSS, with "Impairment" as the most prevalent domain, and LwD, presenting changes in all sections. Vocal signs and symptoms and communicative aspects were shown to have a regular correlation with coping. The correlation between vocal symptoms and communicative aspects was as follows: the greater the impairment in communication, the greater the VoiSS emotional scores and the more they complaint of voice-related signs and symptoms. Conclusion: Patients with PD use all kinds of coping strategies, but prefer using self-control. They present several vocal signs and symptoms, and "Impairment" was the most prevalent domain. There are difficulties in all aspects of communication. The higher the occurrence of vocal signs and symptoms, the more the patient reports the difficulties of living with dysarthria, particularly when deviations affect the emotional domain.
\end{abstract}

\section{RESUMO}

Objetivo: Investigar as estratégias de enfrentamento utilizadas por indivíduos com doença de Parkinson (DP), os sintomas vocais mais relatados, os problemas de comunicação mais presentes e a relação entre o tipo de enfrentamento, os sintomas vocais e os aspectos comunicativos. Métodos: Participaram 73 indivíduos, 33 do grupo experimental, com diagnóstico de DP e apresentando desvio vocal, e 40 do grupo controle (GC), saudáveis, sem desvio vocal. Eles foram submetidos aos seguintes procedimentos: aplicação do Protocolo de Estratégias de Enfrentamento das Disfonias (PEEDBR), da Escala de Sintomas Vocais (ESV) e do Questionário Vivendo com Disartria (VcD). Resultados: O grupo experimental (GE) apresentou desvios em todos os protocolos: PEEDBR, sendo a estratégia de enfrentamento mais utilizada a de "Autocontrole", ESV, com o domínio prevalente "Limitação", e VcD, com alteração em todas as seções. O PEEDBR apresentou correlação regular com a ESV e o VcD. Já entre o Questionário VcD e a ESV, verificouse relação direta entre o escore total do $\mathrm{VcD}$ e o escore total e o domínio emocional da ESV. Conclusão: Pacientes com DP usam todos os tipos de estratégias de enfrentamento, principalmente "Autocontrole". Eles possuem grande quantidade de sinais e sintomas vocais, e "Limitação" foi o domínio mais predominante. Há presença de dificuldades em todos os aspectos que abrangem sua comunicação. Quanto maior a ocorrência de sinais e sintomas vocais, mais o paciente refere ser difícil viver com a disartria, particularmente quando há desvios no domínio emocional.

Study carried out at the Universidade Federal de São Paulo - UNIFESP - São Paulo (SP), Brazil.

(1) Universidade Federal de São Paulo - UNIFESP - São Paulo (SP), Brazil.

(2) Center for Voice Studies - CEV - São Paulo (SP), Brazil.

(3) Associação Brasil Parkinson - ABP - São Paulo (SP), Brazil.

Financial support: Coordenação de Aperfeiçoamento de Pessoal de Nível Superior - CAPES.

Conflict of interests: nothing to declare. 


\section{INTRODUCTION}

Parkinson's disease (PD) is a disorder that causes problems widely described in bodily engines such as bradykinesia, rigidity and resting tremor, and also affects various subsystems involved in the speech process, by hypokinetic dysarthria ${ }^{(1,2)}$. Almost $90 \%$ of patients have problems related to oral communication ${ }^{(3)}$, but the voice is affected more quickly and more often than other subsystems ${ }^{(4)}$ and can be the initial symptom. One-third of patients suffers from dysphonia and presents hoarseness and breathy voice as the most impacting deficit ${ }^{(5)}$.

Usually, communication problems are not caused only by vocal problems, but also by losses reflected in language due to dementia, whose prevalence is estimated in $20-40 \%$ of cases $^{(6)}$, as well as changes in language without association with dementia, which demands special attention from the speech therapist ${ }^{(7)}$.

Treatment of speech and voice disorders in people with PD has been a challenge for professionals, both doctors and speech therapists, and current treatments consist of neuropharmacological therapies, neurosurgical procedures, speech therapy through the approach Lee Silverman Voice Treatment (LSVT ${ }^{\circledR}$ LOUD), which generated data of efficacy and success in the treatment of voice and speech disorders in this population ${ }^{(8)}$, or a combination of methods ${ }^{(9,10)}$. Although there are scientifically proven methods for voice therapy for these individuals, more data on their own perception of voice and communication problem are needed to direct the focus and enhance the therapeutic success.

In recent years, focus have been given to the development and validation of vocal self-assessment questionnaires with different conceptual approaches and evaluative criteria such as quality of life, voice handicap, limitation and restriction on activities, vocal performance, or vocal symptoms ${ }^{(11)}$. They were spread in speech therapy practice as good tools to bring about data on vocal assessment from the patient's point of view, making it important for the therapeutic process to know how these individuals cope with such changes.

Thus, we selected three protocols for this population: the Protocolo de Estratégias de Enfrentamento das Disfonias $(\text { PEED-BR })^{(12)}$, a version translated and adapted from Voice Disability Coping Questionnaire (VDCQ) $)^{(13)}$; the Escala de Sintomas Vocais (ESV) ${ }^{(11)}$, validated for Brazilian Portuguese (BP) from Voice Symptom Scale (VoiSS) ${ }^{(14)}$; and the Questionário Vivendo com Disartria $(\mathrm{VcD})^{(15)}$, translated and adapted from the original Living with dysarthria $(\mathrm{LwD})^{(16)}$.

The use of these three instruments allow us to check how individuals face a vocal problem, what the main vocal symptoms are, and how they live with the problems affecting their communication skills, giving them more information on their quality of life and helping in their vocal treatment by implementing strategies focused on limitations and coping.

The aim of this study was, therefore, to investigate the coping strategies used by individuals with PD, the most commonly reported vocal symptoms, the most common problems of communication, and the relationship between coping strategy, vocal symptoms and communicative aspects.

\section{METHODS}

The study was approved by an institutional Research Ethics Committee (CEP UNIFESP 86962/12) and all participants signed the informed consent.

Study participants were 73 individuals, 33 allocated in the experimental group (EG) - aging between 45 and 93 years, mean age of 73.96 years $(\mathrm{SD}=10.0), 18$ men and 15 women - and 40 subjects in the control group (CG), aging from 53 to 99 years, mean age 72.4 years $(S D=10.9)$, 20 men and 20 women.

Inclusion criteria for EG were diagnosis of PD performed by a neurologist in stages II and III, according to Hoehn \& Yahr scale ${ }^{(17)}$; being stable with their specific medications and presenting hypokinetic dysarthria with focus on dysphonia; confirmation by the perceptual analysis of the general degree of vocal deviation; and also the self-assessment of voice quality through a five-point scale with the following items: excellent, very good, good, fair, and poor. The hearing perceptual analysis was performed by an audiologist specialized in voice, which showed mean degree of deviation as "moderate" (average 65.5 on a 100 -point scale) ${ }^{(18)}$, and "reasonable" was the most common response upon vocal self-assessment (75.8\%), both demonstrating the presence of vocal deviation in individuals with PD.

In CG, inclusion criteria were being a healthy individual, absence of any type of neurological diagnosis, having the same demographic characteristics of EG, and absence of vocal complaints.

Exclusion criteria were the same for both groups: having other laryngeal lesions, no interest or availability to participate in the research, having cognitive disorders and/ or psychiatric disorders that could hinder the protocol application, and/or not understanding instructions. We checked the risk for dementia using the Informant Questionnaire on Cognitive Decline in the Elderly (IQCODE) ${ }^{(19,20)}$, which is an instrument suggested by the Diagnostic and Statistical Manual of Mental Disorders (DSM-IV) for screening dementia, comprising 16 items in which the informer (caregiver or family) evaluates the patient's current performance in different situations of daily life compared to that observed 10 years earlier. Because of this criterion, there was a loss of $14 \%$ of individuals with $\mathrm{PD}$, so the final sample comprised 33 individuals, as mentioned above.

All participants went through the following: application of PEED-BR ${ }^{(12)}, \mathrm{ESV}^{(11)}$, and $\mathrm{VcD}^{(15)}$. The term "communicative aspects" comprises $\mathrm{ESV}^{(11)}$ and $\mathrm{VcD}^{(15)}$. The exemplification of sampling and procedures applied in both groups are shown in Figure 1.

PEED-BR ${ }^{(12)}$ was applied to check the coping strategies used by each group, which is a version translated and adapted from the VDCQ protocol ${ }^{(13)}$. The protocol consists of 10 questions that assess how the subjects react when the condition of their voice is not normal or when they present a voice disorder. It features four coping strategies: reframing, searching for information, self-control, and avoidance/passivity. 
$\mathrm{ESV}^{(11)}$ was used to collect voice signs and symptoms (validated Brazilian-Portuguese version of VoiSS ${ }^{(14)}$, which is an instrument composed of 30 questions comprising three areas: limitation, emotional features, and physical features. Currently, we know that it has a cut-off point on the ROC curve of 16 points, which differentiates dysphonic from healthy people ${ }^{(11)}$. The higher the scores, the greater is the perception of the overall level of voice change with regard to the limitation in their use, emotional reactions, and physical symptoms.

The impact of dysarthria in different situations of communication was verified by the VcD Questionnaire ${ }^{(15)}$, which has been translated and adapted from the original $\mathrm{LwD}^{(16)}$, which comprises 50 questions divided into 10 sections.

Statistical analysis was performed by comparison between groups and correlations between the protocols used. ANOVA, Pearson correlation, and correlation were applied. The significance level for this study was set at 5\% (0.05).

\section{RESULTS}

There were significant differences between groups as to all protocols used in this research.

In PEED-BR ${ }^{(12)}$, all kinds of coping strategies and the total score had higher scores in the EG $(\mathrm{p}<0.001)$, average of 17.45 (Table 1), and the most used coping strategy was "self-control.".

In ESV ${ }^{(11)}$, the EG showed significant differences compared to CG ( $<<0.001$ ), with higher scores in total score (average 45.48) and in all areas of the scale (Table 2). In the EG, the most affected area was the "Limitations" (average 27.88).

The VcD Questionnaire ${ }^{(15)}$ could distinguish groups in all sections, with the highest scores in EG, average of 177.0 (Table 3). When comparing sections, the average differences between the 10 sections were not considered significant in EG, with emphasis on communication difficulties in different aspects in PD patients.

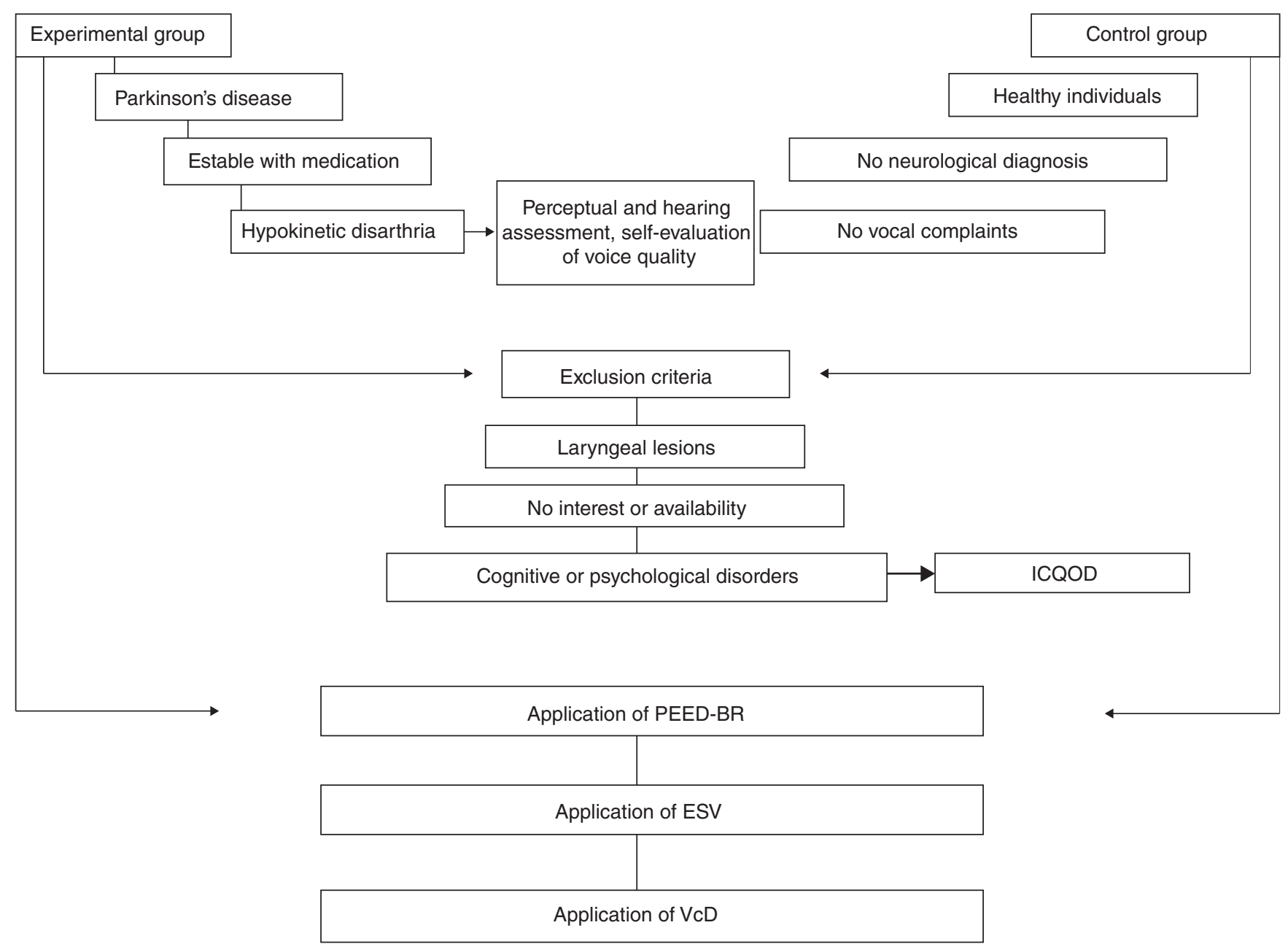

Caption: IQCODE = Informant Questionnaire on Cognitive Decline in the Elderly; PEED-BR = Protocolo de Estratégias de Enfrentamento das Disfonias; ESV = Escala de Sintomas Vocais; $V c D=$ Vivendo com Disartria

Figure 1. Casuistry and procedures applied in control and experimental groups 
Correlations were regular between the results obtained in PEED-BR ${ }^{(12)}$ and scores of $\mathrm{ESV}^{(11)}$ and $\mathrm{VcD}^{(15)}$ (Table 4).

Between $\mathrm{VcD}^{(15)}$ and $\mathrm{ESV}^{(11)}$, there is a good correlation between the total score of $\mathrm{VcD}^{(15)}$ and the total score and the emotional domain of $\mathrm{ESV}^{(11)}$ (Table 5).

\section{DISCUSSION}

Oral communication is key in education, at work, in social life, and self-expression of an individual. The prevalence of communication disorders in about 7 million people with PD is particularly high $(89 \%)^{(10)}$.

The voice is among the first disorders shown in such cases, and can lead individuals to experience social isolation, depression, loss of overall quality of life, and work absenteeism. ${ }^{(21)}$

Table 1. Scores of protocols of coping strategies for disphonia in experimental and control group

\begin{tabular}{|c|c|c|c|c|c|c|}
\hline PEEDBR scores & Mean & SD & Min. & Max. & $\mathrm{n}$ & $p$-value \\
\hline \multicolumn{7}{|c|}{ Seeking information } \\
\hline Control & 0.90 & 2.09 & 0 & 8 & 40 & \multirow[t]{2}{*}{$<0.001$} \\
\hline Experimental & 4.03 & 2.87 & 0 & 10 & 33 & \\
\hline \multicolumn{7}{|l|}{ Resignification } \\
\hline Control & 0.83 & 1.71 & 0 & 6 & 40 & \multirow[t]{2}{*}{$<0.001^{*}$} \\
\hline Experimental & 3.06 & 2.69 & 0 & 10 & 33 & \\
\hline \multicolumn{7}{|l|}{ Self-control } \\
\hline Control & 2.60 & 4.14 & 0 & 15 & 40 & \multirow[t]{2}{*}{$<0.001^{*}$} \\
\hline Experimental & 6.48 & 3.89 & 0 & 14 & 33 & \\
\hline \multicolumn{7}{|c|}{ Avoidance/passivity } \\
\hline Control & 1.98 & 3.42 & 0 & 10 & 40 & \multirow[t]{2}{*}{$0.026^{*}$} \\
\hline Experimental & 3.88 & 3.72 & 0 & 12 & 33 & \\
\hline \multicolumn{7}{|l|}{ Total } \\
\hline Control & 6.30 & 9.82 & 0 & 31 & 40 & \multirow[t]{2}{*}{$<0.001$} \\
\hline Experimental & 17.45 & 9.77 & 0 & 37 & 33 & \\
\hline
\end{tabular}

${ }^{*}$ Significant value $(p<0.05)$ - ANOVA.

Caption: PEEDBR = Protocolo de Estratégias de Enfrentamento nas Disfonias; $\mathrm{SD}=$ standard deviation

Table 2. Total scores and scores according to domains of Escala de sintomas vocais for experimental and control groups

\begin{tabular}{lcccccc}
\hline Scores ESV & Mean & SD & Min. & Max. & $\mathrm{n}$ & $\mathrm{p}$-value \\
\hline Limitation & & & & & & \\
$\quad$ Control & 10.85 & 8.73 & 0 & 35 & 40 & $<0.001^{*}$ \\
$\quad$ Experimental & 27.88 & 9.89 & 13 & 49 & 33 & \\
$\begin{array}{l}\text { Emotional } \\
\text { Control }\end{array}$ & 0.88 & 1.71 & 0 & 8 & 40 & $<0.001^{*}$ \\
$\quad$ Experimental & 9.33 & 7.3 & 0 & 23 & 33 & \\
Physical & & & & & & \\
Control & 6.33 & 3.92 & 0 & 15 & 40 & $0.036^{*}$ \\
$\quad$ Experimental & 8.27 & 3.81 & 2 & 21 & 33 & \\
Total & & & & & & \\
Control & 18.05 & 11.83 & 0 & 49 & 40 & $<0.001^{*}$ \\
Experimental & 45.48 & 17.74 & 18 & 91 & 33 & \\
\hline
\end{tabular}

*Significant value $(p<0.05)$ - ANOVA.

Caption: SD = standard deviation; ESV = Escala de Sintomas Vocais
General quality of life protocols have shown greater impairment in individuals with vocal disorders compared to normal controls, with a worsening of physical, social, and emotional functions, and also mental health ${ }^{(21,22)}$.

However, not only the voice or other subsystems described in hypokinetic dysarthria ${ }^{(1,2)}$ such as breathing, resonance, articulation, and prosody cause a loss in communication. Other factors may also have a negative effect, such as deficits in language and cognition. It is thus necessary to apply protocols of different approaches in order to better describe the damage caused in patients' lives.

PEED-BR ${ }^{(12)}$ shows how an individual copes with a vocal disorder. Coping is the cognitive and behavioral strategy the individual uses to deal with the stress caused by a situation, which can be accomplished through thoughts or actions and can change according to different times of the same stressful situation ${ }^{(12,13,23)}$.

Coping strategies can be divided into emotional and cognitive strategies ${ }^{(12,23)}$. Individuals who use emotional strategies tend to use tools that help them control the emotion or to relieve

Table 3. Scores of the questionnaire Vivendo com disartria for experimental and control groups

\begin{tabular}{|c|c|c|c|c|c|c|}
\hline VcD - Seções & Mean & SD & Min. & Max. & $\mathrm{n}$ & $\mathrm{p}$-value \\
\hline \multicolumn{7}{|l|}{ Total } \\
\hline Control & 106.8 & 41.5 & 50 & 224 & 40 & \multirow{2}{*}{$<0.001^{*}$} \\
\hline Experimental & 177.0 & 51.1 & 71 & 285 & 33 & \\
\hline \multicolumn{7}{|l|}{ 1. Speech } \\
\hline Control & 9.1 & 3.5 & 5 & 18 & 40 & \multirow{2}{*}{$<0.001^{*}$} \\
\hline Experimental & 17.3 & 5.4 & 8 & 29 & 33 & \\
\hline \multicolumn{7}{|c|}{ 2. Language/cognition } \\
\hline Control & 14.5 & 6.3 & 5 & 27 & 40 & \multirow{2}{*}{$0.019^{*}$} \\
\hline Experimental & 17.8 & 5.6 & 8 & 30 & 33 & \\
\hline \multicolumn{7}{|l|}{ 3. Tiredness } \\
\hline Control & 13.2 & 6.2 & 5 & 28 & 40 & \multirow{2}{*}{$0.001^{*}$} \\
\hline Experimental & 18.2 & 5.8 & 7 & 30 & 33 & \\
\hline \multicolumn{7}{|c|}{ 4. Effects on emotion } \\
\hline Controle & 10.8 & 5.2 & 5 & 22 & 40 & \multirow{2}{*}{$<0.001^{*}$} \\
\hline Experimental & 18.8 & 7.3 & 5 & 30 & 33 & \\
\hline \multicolumn{7}{|c|}{ 5. Effects on different people } \\
\hline Control & 8.5 & 4.8 & 5 & 24 & 40 & \multirow{2}{*}{$<0.001^{*}$} \\
\hline Experimental & 14.1 & 7.2 & 5 & 29 & 33 & \\
\hline \multicolumn{7}{|c|}{ 6. Effects on different situations } \\
\hline Control & 9.4 & 4.3 & 5 & 23 & 40 & \multirow{2}{*}{$<0.001^{*}$} \\
\hline Experimental & 16.4 & 6.1 & 5 & 30 & 33 & \\
\hline \multicolumn{7}{|c|}{ 7. Impair possibilities } \\
\hline Control & 9.9 & 6.1 & 5 & 25 & 40 & \multirow{2}{*}{$<0.001^{*}$} \\
\hline Experimental & 18.8 & 7.3 & 5 & 30 & 33 & \\
\hline \multicolumn{7}{|c|}{ 8. Contributes for changes } \\
\hline Control & 10.0 & 4.8 & 5 & 21 & 40 & \multirow{2}{*}{$<0.001^{*}$} \\
\hline Experimental & 17.6 & 6.7 & 5 & 29 & 33 & \\
\hline \multicolumn{7}{|c|}{ 9. How is communication changes? } \\
\hline Control & 10.5 & 6.0 & 5 & 29 & 40 & \multirow{2}{*}{$<0.001^{*}$} \\
\hline Experimental & 18.3 & 6.7 & 5 & 30 & 33 & \\
\hline \multicolumn{7}{|c|}{ 10. Change in the way they speak } \\
\hline Control & 11.0 & 6.2 & 5 & 25 & 40 & \multirow{2}{*}{$<0.001^{*}$} \\
\hline Experimental & 19.7 & 6.4 & 5 & 29 & 33 & \\
\hline
\end{tabular}

${ }^{*}$ Significant value $(p<0.05)$ - ANOVA.

Caption: $\mathrm{VcD}=$ Questionário Vivendo com Disartria; $\mathrm{SD}=$ standard deviation 
it, that is, they use affective strategies to deal with stress. Those who use cognitive coping strategies deal with the problem seeking solutions that change the cause of stress, for example, seeking medical advice ${ }^{(12,13,24)}$.

There were significant differences in scores between groups regarding PEED-BR ${ }^{(12)}$. All kinds of coping strategies such as search for information, self-control, reframing, and avoidance/ passivity had higher scores in the EG. In total score (Table 1), the EG also had higher scores compared to the CG.

Table 4. Correlation of the Protocolo de Estratégias de Enfrentamento das Disfonias with Vivendo com Disartria and Escala de Sintomas Vocais for the experimental group

\begin{tabular}{|c|c|c|c|c|c|}
\hline \multirow{2}{*}{ PEED-BR } & \multirow{2}{*}{$\begin{array}{c}\text { VcD - } \\
\text { Total } \\
\text { Score }\end{array}$} & \multicolumn{4}{|c|}{ ESV } \\
\hline & & Limitation & Emotional & Physical & Total \\
\hline \multirow{2}{*}{\multicolumn{6}{|c|}{$\begin{array}{l}\text { Seeking } \\
\text { information }\end{array}$}} \\
\hline & & & & & \\
\hline Correlation & 20.5 & 57.1 & 35.8 & 16.5 & 50.1 \\
\hline$p$-value & 0.252 & $0.001^{*}$ & $0.041^{*}$ & 0.358 & $0.003^{*}$ \\
\hline \multicolumn{6}{|c|}{ Resignification } \\
\hline Correlation & 27.7 & 18.8 & 26.4 & 41.0 & 30.2 \\
\hline$p$-value & 0.119 & 0.294 & 0.137 & $0.018^{*}$ & 0.088 \\
\hline \multicolumn{6}{|l|}{ Self-control } \\
\hline Correlation & 33.4 & 36.6 & 41.2 & 18.5 & 41.3 \\
\hline$p$-value & 0.058 & $0.036^{*}$ & $0.017^{*}$ & 0.303 & $0.017^{*}$ \\
\hline \multicolumn{6}{|c|}{ Avoidance/passivity } \\
\hline Correlation & 41.4 & 36.8 & 27.0 & 19.4 & 35.8 \\
\hline$p$-value & $0.017^{\star}$ & $0.035^{*}$ & 0.128 & 0.279 & $0.041^{*}$ \\
\hline \multicolumn{6}{|l|}{ Total } \\
\hline Correlation & 42.7 & 50.6 & 44.5 & 30.9 & 53.1 \\
\hline$p$-value & $0.013^{*}$ & $0.003^{*}$ & $0.009^{*}$ & 0.080 & $0.001^{*}$ \\
\hline
\end{tabular}

*Significant value $(p<0.05)-$ Pearson's correlation and correlation test. Caption: PEED-BR = Protocolo de Estratégias de Enfrentamento das Disfonias; $\mathrm{VcD}=$ Questionário Vivendo com Disartria; ESV = Escala de Sintomas Vocais

Table 5. Correlation of Vivendo com Disartria questionnaire and Escala de Sintomas Vocais for the experimental group

\begin{tabular}{lc}
\hline ESV - Group experimental & VcD \\
\hline Limitation & \\
Correlation & 55.6 \\
p-value & $0.001^{*}$ \\
Emotional & \\
Correlation & 63.8 \\
p-value & $<0.001^{*}$ \\
Physical & \\
Correlation & 45.6 \\
p-value & $0.008^{*}$ \\
Total & \\
Correlation & 67.1 \\
p-value & $<0.001^{*}$ \\
\hline
\end{tabular}

*Significant value $(p<0.05)$ - Pearson's correlation and correlation test Caption: $\mathrm{VcD}=$ Vivendo com Disartria questionnaire; $E S V=$ Escala de Sintomas Vocais
When comparing strategies in EG only, the most used coping method was "self-control" (Table 1), which means that individuals need to make an effort to regulate their feelings and actions $^{(12)}$. This strategy is part of the emotional approaches, in which tools are used to control the emotion or alleviate it; in other words, patients use an effective resource to handle stress $^{(12,13,24)}$.

Although the unfavorable impact of voice disorders on quality of life has received much attention recently, little is known about the vocal symptoms that occur and what are the main factors responsible for the drop in overall quality of life $\mathrm{e}^{(25)}$. This aspect is little investigated in voice clinics, but can be a useful tool in the therapeutic process.

Using ESV ${ }^{(11)}$, EG has significant differences compared to CG, with higher scores in total score and in all areas of the scale (Table 2). Analysis of EG only shows that the most affected area is "limitation," which features vocal difficulties present in this group due to hypokinetic dysarthria, such as talking down/ weak and hoarse voice ${ }^{(1,2)}$, with emphasis on other important symptoms such as difficulty in calling people's attention, talking in noisy places, vocal fatigue, among others.

The average vocal signs and symptoms in EG was 45.48 points (Table 2), in a total of 120, and the cut-off note that differentiates patients with vocal problems from those without it, was 16 points $^{(11)}$; thus, the average in EG was nearly three times higher than the cut-off value. In CG (mean age 72.4 years), mean value was 18.05 points; however, this protocol does not have cut-off values for a specific population of seniors, only for the general population. Although vocal complaints or neurological problems were not reported, one should not dismiss vocal disorders related to age, since these are common among older people (prevalence of $29 \%$ ), even without a laryngeal diagnosis ${ }^{(26)}$. Therefore, more specific self-assessment questionnaires and cut-off points for this age group should also be used because it can provide more accurate data on a possible vocal problem.

Gathering these data, namely, the limiting factors of vocal signs and symptoms with the fact that patients predominantly use a coping strategy with more focus on emotion, the probable cause of difficulties and challenges encountered during their rehabilitation process is therefore understood.

As the voice is not the only parameter that impairs oral communication in patients with $\mathrm{PD}$, the VcD Questionnaire ${ }^{(15)}$ was applied to check, beyond the communicative self-reported deficits, its correlation with the other protocols in our study. The $\mathrm{VcD}^{(15)}$ distinguished the groups in all sections with the highest scores in the EG (Table 3). Although this protocol has not been validated, the original one or in Portuguese, the version used in this study was translated and culturally adapted for Brazilian Portuguese. An important aspect that allows to consider the results as at least suitable is that obtained an average 177 points, from a total of 300 , which is similar to that found in the application of this questionnaire in one specific population $^{(15,27)}$.

In EG, comparing sections, average differences between the 10 sections are not significant, although the numerical values are very different (as seen in questions 1,7 , and 10, where 
values are almost doubled), highlighting the communication difficulties in different aspects in PD patients.

Based on these results, one should not give attention only to vocal issues but also to covering the language and impairment in general communication, so we used this self-assessment questionnaire to help in the treatment.

Studies that have implemented self-assessment protocols for PD patients showed a decline in quality of life caused by vocal and communication disorders ${ }^{(15,27-29)}$, showing that the greater the intensity of the disease, the greater the dissatisfaction with one's own voice ${ }^{(28)}$. However, this correlation does not occur with general communication ${ }^{(15)}$, which is changed regardless of disease progression.

Results obtained in PEED-BR ${ }^{(12)}$ have regular correlation with the scores of $\mathrm{ESV}^{(11)}$ and $\mathrm{VcD}^{(15)}$ (Table 4), indicating that having voice-related signs and symptoms and problems in communication does not take the patient to use more coping strategies. This can be explained by the fact that coping is a single factor that has more to do with the life story of the individual than with the signs and symptoms and aspects of communication for this population. The correlation between coping and vocal symptoms, but with the use of other specific protocol, did not show results either even among patients with behavioral dysphonia ${ }^{(30)}$.

This finding reinforces the need to educate the patient as to how voice signs and symptoms can be an important sign of voice overuse and how much it can increase the risk of a worsening in communications ${ }^{(30)}$. It also shows that one cannot ignore the approach of indirect therapy such as orientation and vocal hygiene, even in individuals with neurological and degenerative disease.

The correlation of $\mathrm{VcD}^{(15)}$ with $\mathrm{ESV}^{(11)}$ (Table 5) was considered good between the total score of $\mathrm{VcD}$ and the total score and emotional field of ESV, indicating that the greater the loss in communication, the more symptoms and signs are self-reported, and the greater emotional deficit is produced. Added to these results, sensory and perceptual difficulties found in PD patients may postpone the search for rehabilitation, stressing the importance of applying ESV and $\mathrm{VcD}$, in order to actively pursue the perception of signs, symptoms, and their impact on quality of life.

PD has its symptoms extensively described and studied. Within the speech perspective, the main features and aspects of the disease are known to affect the voice and communication, but the assessment and, therefore, treatment should not be based only on general knowledge of what has already been pointed out in the literature. It is very important to know how patients cope with their voice and communication problems, how they deal with their voice symptoms, which often fall short of those seen and characterized by the disease only, as well as how their communication is impacted, so that we can help them build a better quality of life.

\section{CONCLUSION}

PD patients use several coping strategies, with emphasis to "self-control." They present many vocal signs and symptoms, with "limitation" being the most prevalent domain. They find difficulties in all aspects of communication. We also noted that when the occurrence of vocal signs and symptoms is higher, particularly in the emotional domain, more patients report the difficulties of living with dysarthria.

\section{ACKNOWLEDGMENT}

To the Coordination for the Improvement of Higher Education Personnel (CAPES), for financing this research.

*FPC participated in study design, data collection and analysis, and writing; GD participated in study design, data collection, and proofreading of the paper; $M B$ participated in study design, data analysis, writing, and proofreading of the article.

\section{REFERENCES}

1. Darley FL, Aronson AR, Brown JR. Clusters of deviant speech dimensions in the dysarthrias. J Speech Hear Res. 1969a;12(3):462-96.

2. Darley FL, Aronson AR, Brown JR. Differential diagnostic patterns of dysarthria. J Speech Hear Res. 1969b;12(2):246-69.

3. Zarzur AP, Duarte IS, Goncalves Gdo N, Martins MA. Laryngeal electromyography and acoustic voice analysis in Parkinson's disease: a comparative study. Braz J Otorhinolaryngol. 2010;76(1):40-3.

4. Ho AK, Iansek R, Marigliani C, Bradshaw JL, Gates S. Speech impairment in a large sample of patients with Parkinson's disease. Behav Neurol. 1998;11(3):131-7.

5. Sewall GK, Jiang J, Ford CN. Clinical evaluation of Parkinson's related dysphonia. Laryngoscope. 2006;116(10):1740-4

6. Cummings JL. Intellectual impairment in Parkinson's disease: clinical, pathologic, and biochemical correlates. J Geriatr Psychiatry Neurol. 1988:1(1):24-36.

7. Prieto F, Radanovic M, Schmitt C, Barbosa ER, Mansur LL. Compreensão de sentenças na doença de Parkinson. Dement Neuropsychol. 2007;1(4):386-91.

8. Ramig LO, Pawlas A, Countryman S. The Lee Silverman Voice Treatment (LSVT): A Practical Guide to Treating the Voice and Speech Disorders in Parkinson Disease. Yowa: National Center for Voice and Speech; 1995.

9. Schultz GM, Grant MK. Effects of speech therapy and pharmacologic and surgical treatments on voice and speech in Parkinson's disease: a review of the literature. J Commun Disord. 2000;33(1):59-88.

10. Ramig LO, Fox C, Sapir S. Speech treatment for Parkinson's disease. Expert Review of Neurotherapeutics. 2008;8(2):297-309.

11. Moreti F, Zambon F, Oliveira G, Behlau M. Crosscultural adaptation, validation, and cutoff values of the Brazilian Version of Voice Symptoms Scale VoiSS. J Voice. 2014;28(4):458-68.

12. Oliveira G, Hirani SP, Epstein R, Behlau M. Coping strategies in voice disorders of a Brazilian Population. J Voice. 2012;26(2):205-13.

13. Epstein R, Hirani SP, Stygall J, Newman SP. How Do Individuals Cope With Voice Disorders? Introducing the Voice Disability Coping Questionnaire. J Voice. 2009;23(2):209-17.

14. Deary IJ, Wilson JA, Carding PN, MacKenzie K. VoiSS: a patientderived Voice Symptom Scale. J Psychosom Res. 2003;54(5):483-9.

15. Puhl A, Diaferia G, Padovani M, Behlau M. Autoavaliação das disartrias em pacientes com doença de Parkinson. Apresentado no $17^{\circ}$ Congresso Brasileiro de Fonoaudiologia e $1^{\circ}$ Congresso IberoAmericano de Fonoaudiologia; 2009 Out 21-24; Salvador, BA.

16. Hartelius L, Elmberg M, Holm SR, Lovberg AS, Nikolaidis S. Living with dysarthria: evaluation of a selfreport questionnaire. Folia Phoniatr Logop. 2008;60(1):11-9.

17. Fahn S, Elton RL. Unified Parkinson's disease rating scale. In: Fahn S, Marsden CD, Calne DB, Goldstein M, editors. Recent developments in Parkinson's disease. New Jersey: Macmillan Health Care Information; 1987. p. 153-63, 293-304. 
18. Yamasaki R, Leão S, Madazio G, Padovani M, Azevedo M, Behlau M. Correspondência entre escala analógicovisual e escala numérica na avaliação perceptivoauditiva de vozes. Apresentado no $16^{\circ}$ Congresso Brasileiro de Fonoaudiologia; 2008 Set 24-27; Campos do Jordão, SP. Rev Soc Bras Fonoaudiol. 2008;13(supl.): 1080.

19. Jorm AF. A short form of the Informant Questionnaire on Cognitive Decline in the Elderly (IQCODE): development and crossvalidation. Psychol Med. 1994;24:145-53.

20. Sanchez MAS, Lourenço RA. Informant Questionnaire on Cognitive Decline in the Elderly (IQCODE): adaptação transcultural para uso no Brasil. Cad Saúde Pública. 2009;25(7):1455-65.

21. Cohen SM, Dupont WD, Courey MS. Qualityoflife impact of nonneoplastic voice disorders: a metaanalysis. Ann Otol Rhinol Laryngol. 2006;115(2):128-34.

22. Benninger MS, Ahuja AS, Gardner G, Grywalski C. Assessing outcomes for dysphonic patients. J Voice. 1998;12(4):540-50.

23. Lazarus RS, Folkman S. Stress, appraisal and coping. New York: Springer Publishing Company; 1984.
24. Folkman S, Lazarus RS. Manual for the ways of coping questionnaire. Palo Alto, CA: Consulting Psychologist Press; 1980.

25. Merrill RM, Roy N, Lowe J. Voicerelated symptoms and their effects on quality of life. Ann Otol Rhinol Laryngol. 2013;122(6):404-11.

26. Roy N, Stemple J, Merrill RM, Thomas L. Epidemiology of voice disorders in the elderly: preliminary findings. Laryngoscope. 2007;117(4):628-33.

27. Padovani M, Behlau M. Medidas perceptivoauditivas e acústicas de voz e fala e autoavaliação da comunicação nas disartrias [tese]. São Paulo: Universidade Federal de São Paulo; 2011.

28. Silva LF, Gama AC, Cardoso FE, Reis CA, Bassi IB. Idiopathic Parkinson's disease: vocal and quality of life analysis. Arq Neuropsiquiatr. 2012;70(9):674-9.

29. Louis ED, Gerbin M. Voice handicap in essential tremor: a comparison with normal controls and Parkinson's disease. Tremor Other Hyperkinet Mov (N Y). 2013; 3. pii: tre03-114-970-1.

30. Zambon F, Moreti F, Behlau M. Coping Strategies in Teachers With Vocal Complaint. J Voice. 2014;28(3):341-8. 